\title{
A prospective study of comparison between transvaginal sonogram and histopathological examination in perimenopausal women with abnormal uterine bleeding
}

\author{
P. Rishma Priyanka*, C. Rama Mani, A. Yamuna
}

Department of Obstetrics and Gynecology, Narayana Medical College and Hospital, Nellore, Andhra Pradesh, India

Received: 25 September 2019

Accepted: 05 October 2019

\section{*Correspondence:}

Dr. P. Rishma Priyanka,

E-mail: rishmapriyanka7@gmail.com

Copyright: () the author(s), publisher and licensee Medip Academy. This is an open-access article distributed under the terms of the Creative Commons Attribution Non-Commercial License, which permits unrestricted non-commercial use, distribution, and reproduction in any medium, provided the original work is properly cited.

\begin{abstract}
Background: Abnormal uterine bleeding is one of the most frequently encountered conditions in gynaecology practice and forms about $10 \%$ of all gynaecological admissions, the main concern in perimenopausal bleeding is that the bleeding could be the only external manifestation of many hidden serious pathologies of uterine-cavity. The objective of this study was to compare the results of transvaginal sonography (TVS) and drug and cosmetic (D and C) with histopathological examination (HPE) report of hysterectomy specimen in perimenopausal women with AUB.

Methods: A prospective comparative study where 100 perimenopausal women with AUB were subjected to TVS then $\mathrm{D}$ and $\mathrm{C}$ and then the results were compared with histopathological report of the hysterectomized specimen.

Results: With an endometrial thickness less than or equal to $15 \mathrm{~mm}$ the histopathology report is normal endometrium. When the endometrial thickness more than or equal to $15 \mathrm{~mm}$ the histopathology report is hyperplasia or carcinoma. Findings of TVS correlated well with histopathological report after hysterectomy. 14 cases of adenomyosis, 16 cases of myomatous polyp, and 6 cases of endometrial polyp missed by dilatation and curettage.

Conclusions: TVS is a simple, non-invasive test to indirectly visualize the endometrial cavity and is useful as a first step diagnostic procedure in the evaluation of perimenopausal bleeding. Dilatation and curettage lags in detecting adenomyosis, endometrial and myomatous polyps, When TVS combined with dilatation and curettage, it can supplement the shortcomings of dilatation and curettage.
\end{abstract}

Keywords: Perimenopausal bleeding, Transvaginal sonography, Drug and Cosmetic, histopathological examination report

\section{INTRODUCTION}

Abnormal uterine bleeding is one of the most frequently encountered conditions in gynaecology practice and forms about $10 \%$ of all gynaecological admissions. In the perimenopausal period, the menstrual cycles tend to become anovulatory and acyclical, with unopposed estrogen secretion leading to hyperplasia of the proliferative endometrium Kurman RJ et al. ${ }^{1}$ The main concern in perimenopausal bleeding is that the bleeding could be the only external manifestation of many hidden serious pathologies of uterine-cavity.

The main cause of perimenopausal bleeding include endometrial hyperplasia $15-25 \%$, dysfunctional uterine bleeding $15-20 \%$, benign lesion of the uterus-myomas $10 \%$, malignancies of the reproductive tract $10-15 \%$, malignancies of the reproductive tract $10-15 \%$, adenomyosis $2-4 \%$, exogenous estrogen therapy $3-5 \%$, miscellaneous causes (endometrial polyps, endometritis, 
cervical polyp and erosion, pregnancy related causes) $10 \%$.

In 1969, a total number of 6907 dilatation and curettage were reviewed and the concept arrived was that the curettage was simple, harmless, and easy to perform, that it may be done by the newest intern without difficulty. Under general anaesthesia it also provides an ideal opportunity for thorough examination of pelvic organs Mc Elin et al. ${ }^{2}$ A simple day-care procedure, dilatation and curettage, is a standard procedure for diagnosis which is used for histological evaluation of the endometrium. Previously, it used to be considered as the gold standard procedure for the patients of AUB, but now, it has its drawbacks like small lesions which are focal can be missed with this blind procedure and has a failure rate of $12-30 \% .^{3}$ With advent of TVS, gynaecologist now has a simple outpatient method of studying endometrium for detecting malignant lesion or their precursors at an earlier stage. The thickness and internal echotexture of the endometrium in the various phases of the menstrual cycle as seen in TVS correlates well with endometrial histology. Lewin et al, showed that transvaginal sonogram can reliably diagnose endometrial thickness greater than $5 \mathrm{~mm}$ to be $100 \%$ sensitive and $64 \%$ specific in identifying endometrial pathology Lewin et al. ${ }^{4}$

Endometrial carcinoma can be diagnosed at an earlier stage, other pathologic conditions of the endometrium and myometrium such as myomatous polyps, endometrial polyps, adenomyosis are also well visualized. Thus, with TVS the endometrial pathology can be visualized, whereas fractional curettage is a blind procedure. Thus, the TVS can be used as a better diagnostic procedure as it supplements the shortcomings of fractional curettage. Malinova $M$ and Pehlivanov et al, adopted the transvaginal approach to increase the accuracy of diagnosis Malinova et al. $^{5}$ This study proposes to correlate the finding of the two diagnostic modalities used in the evaluation of women with perimenopausal bleeding namely, TVS and histopathological examination.

Objectives of this study were to determine the accuracy of TVS in detecting endometrial pathology like endometrial or myomatous polyps and abnormal endometrial architecture like hyperplasia and endometrial carcinoma in perimenopausal women with bleeding per vagina. To compare the thickness of endometrium in patients with perimenopausal bleeding with their histopathology reports.

\section{METHODS}

This study is a prospective and comparative study carried out from 2017 to 2019 in 100 perimenopausal women with AUB attending Narayana General Hospital, Nellore.

\section{Inclusion criteria}

- $\quad$ The patients $>40$ years of age

- Not yet attained menopause

- Uterus was normal to 12 weeks size and adnexa were clinically normal.

\section{Exclusion criteria}

- Patients with carcinoma cervix, fibroids, polyps, adnexal swellings

- Patients on oral contraceptive pills

- Patients with blood dyscrasias.

The transducer was introduced into the posterior vaginal fornix. The uterus was scanned in long axis and coronal views with special emphasis on endometrium. The scanning of the uterus was first done in the sagittal plane from fundus to the internal os then. The regularity, length, anteroposterior measurements, transverse dimensions, anteroposterior endometrial thickness of uterus were measured and endometrial volume calculated. Uterine cavity examined systematically in both sagittal and coronal views for the presence of submucous fibroid polyps, endometrial polyps, adenomyosis or abnormal endometrial architecture. The entire pelvis along with uterus was additionally examined to rule out any other pathology.

$\mathrm{D}$ and $\mathrm{C}$ was performed in all these patients. Under aseptic precautions, in lithotomy position, perineum was painted and draped. After a per vaginal examination, Endocervical curetting was taken. Uterus length was measured with uterine sound and the length was noted. After serial dilatation of cervix, with a blunt curette all quadrants curetted thoroughly and were sent for histopathological examination in formalin. The biopsy reports were studied.

Endometrial pattern studied in TVS were correlated with histopathological reports. Almost all of these patients underwent hysterectomy either abdominal or vaginal, the results were correlated with histopathological report of hysterectomy specimen.

\section{Statistical analysis}

Results of TVS are checked for sensitivity, specificity, positive predictive value and negative predictive value in contingency table for statistical analysis.

\section{RESULTS}

More than $60 \%$ of the patients with AUB in the study group belongs to 41-45 years of age. $30 \%$ belongs to $46-$ 50 years of age. $8 \%$ belongs to 51-55 years of age (Figure $1)$.

About $72 \%$ of patients with AUB had endometrial thickness $<15 \mathrm{~mm}$. 


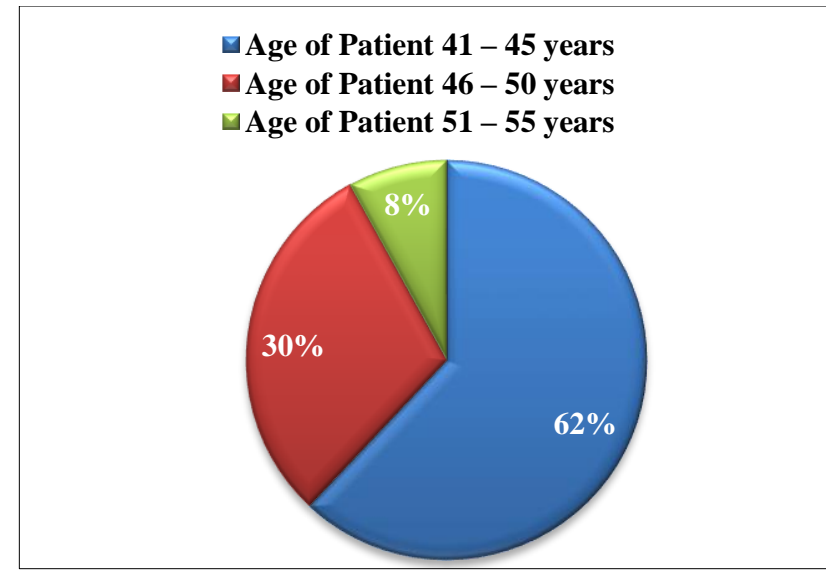

Figure 1: Age distribution of perimenopausal women with bleeding per vagina in the study group.

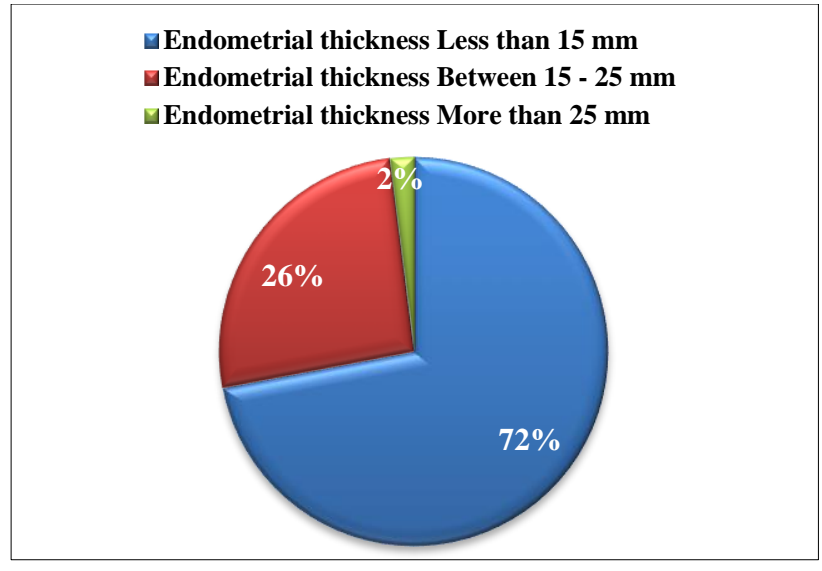

Figure 2: Endometrial thickness measurement by using TVS.

Table 1: Associated finding in TVS.

\begin{tabular}{|llll|}
\hline Associated pelvic findings & Number of patients & Percentage & Cumulative percentage \\
\hline Adenomyosis & 14 & 14.0 & 14.0 \\
\hline Myomatous polyp. & 16 & 16.0 & 30.0 \\
\hline Ovarian cyst. & 4 & 4.0 & 34.0 \\
\hline Endometrial polyp. & 6 & 6.0 & 40.0 \\
\hline Endometrial abnormalities & 4 & 4.0 & 44.0 \\
\hline Normal & 56 & 56.0 & 100.0 \\
\hline Total & $\mathbf{1 0 0}$ & $\mathbf{1 0 0 . 0}$ & \\
\hline
\end{tabular}

$26 \%$ of patients with AUB had endometrial thickness of $15-25 \mathrm{~mm}$.

Only $2 \%$ with AUB had endometrial thickness more than $25 \mathrm{~mm}$ (Figure 2). 14\% of perimenopausal women have associated adenomyosis and only $6 \%$ of endometrial polyp, $4 \%$ had ovarian cyst, $16 \%$ had myometrial polyp, endometrial abnormalities are found in $4 \%$ and $56 \%$ patients had normal endometrium on TVS (Table 1).

With an endometrial thickness less than or equal to 15 $\mathrm{mm}$, the histopathology report is normal endometrium. When the endometrial thickness more than or equal to 15 $\mathrm{mm}$, the histopathology report is hyperplasia or carcinoma.

Table 2: Comparison of histopathology results with the endometrial thickness measured in TVS.

\begin{tabular}{|lllll|}
\hline Histopathology report & $\begin{array}{l}\text { Mean endometrial } \\
\text { thickness in mm }\end{array}$ & No. of patients & Percentage & Cumulative percentage \\
\hline NSE & $8.4(5-10)$ & 58 & 58.0 & 58.0 \\
\hline SE & $10.8(10-13)$ & 14 & 14.0 & 72.0 \\
\hline CGH & $17.1(16-19)$ & 20 & 20.0 & 92.0 \\
\hline Adenomatous hyperplasia & 20 & 2 & 2.0 & 94.0 \\
\hline Atypical hyperplasia & 23 & 1 & 1.0 & 95.0 \\
\hline Endometritis & 11 & 3 & 3.0 & 98.0 \\
\hline Endometrial carcinoma & 27 & 2 & 2.0 & 100.0 \\
\hline Total & & $\mathbf{1 0 0}$ & $\mathbf{1 0 0 . 0}$ & \\
\hline
\end{tabular}

On HPE report 58\% had NSE, $10.8 \%$ had SE, $17.1 \%$ had $\mathrm{CGH}$, adenomatous hyperplasia in $2 \%$, atypical hyperplasia in $1 \%$, endometritis in $3 \%$, endometrial carcinoma in $2 \%$ patients of the study group (Table 2 ). 
Findings of TVS correlated well with histopathological report after hysterectomy.

A 14 cases of adenomyosis, 16 cases of myomatous polyp, and 6 cases of endometrial polyp missed by dilatation and curettage.

The 50 patients with normal endometrium thickness less than or equal to $15 \mathrm{~mm}$ on TVS, had report of NSE (38) and SE in both $\mathrm{D}$ and $\mathrm{C}$ report and hysterectomy specimen HPE report. ${ }^{12}$

The 30 patients with Endometrial thickness more than or equal to $15 \mathrm{~mm}$ on TVS had $\mathrm{CGH}$ and adenomatous hyperplasia in both $\mathrm{D}$ and $\mathrm{C}$ report and hysterectomy specimen HPE report. ${ }^{2,8}$

A 14 patients with adenomyosis on TVS confirmed with hysterectomy HPE report had reports of NSE and CGH in $\mathrm{D}$ and $\mathrm{C}$ report and hysterectomy specimen HPE report as well. ${ }^{7}$

The 16 cases of myomatous polyp on TVS are missed both in D and $\mathrm{C}$ and hysterectomy specimen HPE report. 6 cases of endometrial polyp on TVS are missed in D\&C reported in hysterectomy HPE report.

Table 3: Comparison of TVS findings with histopathologic diagnosis of fractional curettage and hysterectomy.

\begin{tabular}{|c|c|c|c|}
\hline Ultrasonographic findings & Number of patients & DC-HPE report & Hysterectomy HPE report \\
\hline $\begin{array}{l}\text { Normal endometrium thickness less } \\
\text { than or equal to } 15 \mathrm{~mm}\end{array}$ & 50 & $\begin{array}{l}\text { 38-N.S.E. } \\
\text { 12-S.E. }\end{array}$ & $\begin{array}{l}\text { 28-N.S.E. } \\
\text { 6-S.E. } \\
\text { 16-Followed up with } \\
\text { transvaginal sonogram }\end{array}$ \\
\hline $\begin{array}{l}\text { Endometrial thickness more than or } \\
\text { equal to } 15 \mathrm{~mm}\end{array}$ & 10 & $\begin{array}{l}\text { 8-C.G.H } \\
\text { 2-Adenomatous } \\
\text { hyperplasia }\end{array}$ & $\begin{array}{l}\text { 8-C.G.H } \\
\text { 2-Adenomatous hyperplasia }\end{array}$ \\
\hline Adenomyosis & 14 & $\begin{array}{l}\text { 7-N.S.E. } \\
\text { 7- C.G.H }\end{array}$ & 14-Adenomyosis \\
\hline Myomatous polyp & 16 & $\begin{array}{l}\text { 12-N.S.E. } \\
\text { 2- C.G.H } \\
\text { 2-Atypical hyperplasia }\end{array}$ & $\begin{array}{l}\text { 12-N.S.E. } \\
\text { 2-C.G.H } \\
\text { 2-Atypical hyperplasia }\end{array}$ \\
\hline Endometrial polyp & 6 & 6-N.S.E. & $\begin{array}{l}\text { 6-Endometrial Polyp } \\
\text { with N.S.E. }\end{array}$ \\
\hline Endometritis & 2 & 2-Endometritis & 2-Endometritis \\
\hline Endometrial carcinoma & 2 & 2-Adenocarcinoma & 2-Lost for follow-up \\
\hline Total & 100 & & \\
\hline
\end{tabular}

The 2 cases each detected as endometritis and endometrial carcinoma are detected as same both on TVS and $\mathrm{D}$ and $\mathrm{C}$, among which endometritis proven on hysterectomy specimen HPE report (Table 3).

\section{DISCUSSION}

A TVS measured endometrial thickness of $15 \mathrm{~mm}$ and less was associated with normal, active endometrium in the histopathological report. Endometrial hyperplasia and carcinoma were found only among those women whose endometrial thickness was greater than $15 \mathrm{~mm}$.

The 'classification tree' method was used to identify the cutoff values of sonographic endometrial thickness that could be indicative of a class of uterine pathology. No case of endometrial cancer was found with a cutoff point of $5 \mathrm{~mm}$ endometrial thickness, whereas all patients with endometrial thickness more than $15 \mathrm{~mm}$ at transvaginal sonogram had an endometrial carcinoma. In a group of patients with endometrial thickness between 6 and 14 $\mathrm{mm}$, they found a normal atrophic endometrium, benign and malignant pathology. ${ }^{6}$

The sensitivity in detecting endometrial malignancy was $94.44 \%$ for endometrial biopsy and $100 \%$ for TVS when the endometrial thickness was more than $8 \mathrm{~mm}$.

Getpook et al, proposed that endometrial thickness of $8 \mathrm{~mm}$ or less has less chance of association with malignant pathologies in perimenopausal uterine bleeding. ${ }^{7}$

The ultrasonographic findings correlated well with the pathological report of the hysterectomy specimen.

The sensitivity in detecting endometrial malignancy was $94.44 \%$ for endometrial biopsy and $100 \%$ for transvaginal sonogram when the endometrial thickness was more than $8 \mathrm{~mm}$ Chiferi $\mathrm{G}$ et al. ${ }^{8}$ 


\section{The results obtained were with}

- Sensitivity of $92.66 \%$

- Specificity of $100 \%$

- Positive predictive value of $100 \%$

- Negative predictive value of $97.73 \%$

- Diagnostic accuracy of $98.3 \%$.

A study conducted by Jain et al, showed that sensitivity, specificity, PPV, and NPV of adenomyosis were $33.33 \%$, $97.87 \%, 50 \%$, and $95.83 \%$, respectively. The sensitivity of polyp was $62.5 \%$; specificity was $95.83 \%$; the PPV was $71.42 \%$; the NPV was $93.02 \%$. Fibroids had sensitivity, specificity, PPV, and NPV of $75 \%, 97.82 \%$, $75 \%$, and $97.82 \%$, respectively, which was comparable with our study. Endometrial hyperplasia had sensitivity, specificity, PPV, and NPV of $81.81 \%, 92.3 \%, 75 \%$, and $94.73 \%$, which were concordant to our study. ${ }^{9}$

\section{CONCLUSION}

TVS is a simple, non-invasive test to indirectly visualize the endometrial cavity and is useful as a first step diagnostic procedure in the evaluation of perimenopausal bleeding.

Dilatation and curettage lags in detecting adenomyosis, endometrial and myomatous polyps, and when TVS combined with dilatation and curettage, it can supplement the shortcomings of dilatation and curettage and an endometrial thickness of more than $8 \mathrm{~mm}$ better be evaluated with dilatation and curettage.

This study proves that TVS correlates well with the histopathology findings.

Funding: No funding sources

Conflict of interest: None declared

Ethical approval: The study was approved by the Institutional Ethics Committee

\section{REFERENCES}

1. Kurman RJ, Kaminski PF, Norris HJ. The behavior of endometrial hyperplasia a long-term study of untreated hyperplasia in 170 patients. Cancer. 1985;56:403-12.

2. Mc Ellin TW, Burd CC, Reeves BD. Diagnostic dilatation and curettage. J Obstet Gynecol. 1969;33:807.

3. Pillai S. Sonographic and histopathological correlation and evaluation of endometrium in perimenopausal women with abnormal uterine bleeding. Int J Reprod Contracept Obstet Gynecol. 2014;3:113-7

4. Lewin A, Gabis L, Ushakov F, Anteby SA, Endometrial measurement by transvaginal sonography in post-menopausal bleeding, Harefuah. 1996;130(10):662-8.

5. Malinova, Pehlivano V. Trans vaginal sonography and endometrial thickness in patients with postmenopausal uterine bleeding. $\mathrm{Eu} \mathrm{J}$ Obstet Gynaecol Repro Biol. 1995;58(2):161-5.

6. Loverro G, Bettocchi S, Cormio G, Nicoloardiv. Transvaginal sonography and hysteroscopy in postmenopausal uterine bleeding. Marturitas. 1999;33(2):139-44.

7. Get Pook C, Wattanakumtornkill S. Endometrial thickness screening in premenopausal women with abnormal uterine bleeding. J obstet Gynaecol Res. 2006;32(6):588-92.

8. Guisa-Chiferi MG, Gonfolalva WJ, Baract EC, Transvaginal ultrasound, uterine biopsy and hysteroscopy for postmenopausal bleeding. Int $\mathbf{J}$ Gynaecol Obstet. 1996;55(1):39-44.

9. Choudhary J, Acharya V, Jain M. Evaluation of abnormal uterine bleeding with transvaginal sonography and hysteroscopy in perimenopausal women. Int J Reprod Contracept Obstet Gynecol. 2017;6:3607-13.

Cite this article as: Priyanka PR, Mani CR, Yamuna A. A prospective study of comparison between transvaginal sonogram and histopathological examination in perimenopausal women with abnormal uterine bleeding. Int J Reprod Contracept Obstet Gynecol 2019;8:4233-7. 